\title{
Finger Replantation Optimization Study (FRONT): Update on National Trends
}

\author{
Hoyune E. Cho, MD ${ }^{1}$ [Postdoctoral Research Fellow], Lin Zhong, MD, MPH ${ }^{2}$ [Research \\ Analyst], Sandra V. Kotsis, MPH $^{3}$ [Research Coordinator], and Kevin C. Chung, MD, MS ${ }^{4}$ \\ [Professor of Surgery, Assistant Dean for Faculty Affairs] \\ 1.Section of Plastic Surgery, Department of Surgery, University of Michigan Medical School, Ann \\ Arbor, MI \\ 2.Section of Plastic Surgery, Department of Surgery, University of Michigan Medical School, Ann \\ Arbor, MI \\ 3.Section of Plastic Surgery, Department of Surgery, University of Michigan Medical School, Ann \\ Arbor, MI \\ 4. Section of Plastic Surgery, Department of Surgery, Michigan Medicine, Ann Arbor, MI
}

\section{Abstract}

Purpose: Traumatic digit amputations have an adverse impact on patients' daily living. Despite experts advocating for digit replantation, studies have shown a continued decrease in rate of replantation. We performed a national-level investigation to examine the recent trend of practice for digital replantation.

Methods: We used the National Inpatient Sample database under the Healthcare Cost and Utilization Project to select adult patients with traumatic digit amputation from 2001 to 2014. We calculated the rate of attempted and rate of successful digit replantation per year, subcategorizing for digit type (thumb or finger) and for hospital type (rural, urban non-teaching, or urban teaching). We also analyzed the pattern of distribution of case volume to each hospital type per year. We used two multivariable logistic regression models to investigate patient demographic and hospital characteristics associated with the odds of replantation attempt and success.

Results: Among the 14,872 adult patients with a single digit amputation from 2001 to 2014, only $1,670(11.2 \%)$ underwent replantation. The rate of replantation attempt trended down over the years for both thumb and finger injuries at all hospital types, despite increasing proportions of cases being sent to urban teaching hospitals where they were more than twice as likely to undergo replantation. The rate of successful replantation stayed stable for thumb at $82.9 \%$ and increased for fingers from $76.1 \%$ to $82.4 \%$ over the years. Patients were more likely to undergo replantation

Corresponding Author: Kevin C. Chung, MD, MS, Section of Plastic Surgery, Michigan Medicine, 1500 E. Medical Center Drive, 2130 Taubman Center, SPC 5340, Ann Arbor, MI 48109-5340, Phone: 734-615-3435, Fax: 734-763-5354,

kecchung@med.umich.edu.

Publisher's Disclaimer: This is a PDF file of an unedited manuscript that has been accepted for publication. As a service to our customers we are providing this early version of the manuscript. The manuscript will undergo copyediting, typesetting, and review of the resulting proof before it is published in its final citable form. Please note that during the production process errors may be discovered which could affect the content, and all legal disclaimers that apply to the journal pertain. 
if they had private insurance or had a higher level of income. Neither hospital case volume nor hospital type were predictive of successful replantation.

Conclusions: Although more single digit amputations were treated by urban teaching hospitals with higher likelihood to replant, the downward trend in rate of attempt regardless of hospital type demonstrates that concentration of case volume is not the solution to reverse the declining trend.

\section{Keywords}

Digit replantation; health policy; national trend; resource allocation

One out of ten visits to the emergency department is for an injury to the hands or fingers. ${ }^{1}$ In fact, there were 4 million cases reported in 2015 alone. ${ }^{1}$ Among various hand injuries, traumatic digit amputations occur mostly in young, working patients and adversely affect patients' physical function and emotional well-being. ${ }^{2}$ With a prolonged course of recovery and time away from work, hand injuries impose high productivity costs that cause considerable economic burden to the community. ${ }^{3}$

Replantation of amputated digits can restore both function and appearance. Patients with successfully replanted fingers report less pain, better functional outcome, enhanced appearance, greater long-term quality of life, and improved patient satisfaction compared to those with revision amputations. ${ }^{4-6}$ A survey analysis also showed that patients prefer replantation over revision amputation. ${ }^{7}$ However, in the U.S., hand and microvascular services are limited and inconsistently available. ${ }^{8}, 9$ In 2012, only $55 \%$ of level I and $29 \%$ of level II trauma centers offered immediate access to digit replantation service. ${ }^{9}$ Moreover, only half of hand surgeons certified in microsurgery actually performed digit replantation. ${ }^{10}$ Even among those who provide replantation, the majority performed fewer than five cases per year. ${ }^{10}$ Despite advances in trauma care, microsurgical techniques, and the support of national surgical societies, the rate of replantation in the U.S. has decreased in the past. ${ }^{11-18}$ Furthermore, an analysis of data up to 2012 showed that the U.S. had a pattern of decentralization of cases away from high-volume hospitals. ${ }^{15}$

In 2013, the American College of Surgeons mandated that level-1 trauma centers have microvascular services available at all times. ${ }^{19}$ To assess the recent trend of digit replantation in the U.S., we conducted a retrospective cohort study with a large, national database. We hypothesize that the rate of attempt of replantation and the rate of successful initial vascularization for single digit amputations has continued to decrease. We also examined patient demographic and hospital characteristics correlated to the rate of digit replantation.

\section{Materials and Methods}

\section{Data Source}

We investigated claims data from the National Inpatient Sample (NIS) database under the Healthcare Cost and Utilization Project, the largest U.S. database of inpatient hospital stays that collects information from all insurance payers. The NIS contains data on a stratified sample of over 1,000 hospitals with approximately 8 million inpatient admissions captured 
per year. ${ }^{20}$ We selected the NIS database for our study because digit replantation cases are associated with inpatient stays in the U.S. We used the most updated dataset available at the time of analysis (2001-2014). Our retrospective study based on claims data was exempt from Institutional Review Board oversight.

\section{Study Cohort Selection}

We included patients 18 years of age or older, who experienced traumatic amputation of a single digit and underwent either a revision amputation or replantation, using the International Classification of Diseases, Ninth Revision, Clinical Modification (ICD-9-CM) codes. We used 885.0 (traumatic amputation of thumb), 885.1 (traumatic amputation of thumb, complicated), 886.0 (traumatic amputation of other fingers), and 886.1 (traumatic amputation of other fingers, complicated) to define the diagnosis of traumatic digit amputation. Replantation was defined by 84.21 (thumb reattachment) and 84.22 (finger reattachment), and revision amputation was defined by 84.01 (amputation and disarticulation of finger), 84.02 (amputation and disarticulation of thumb), 84.3 (revision of amputation stump), and 86.22 (excisional debridement of wound, infection, or burn). We included 86.22 to capture amputation cases that were debrided and closed and were thus coded this way. We excluded claims with more than one digit amputation diagnosis code because of the inability of the ICD-9 coding scheme to discern the procedure each digit underwent and the success or failure of each replanted digit. ${ }^{15}$

\section{Study Variables}

The primary outcomes were the rate of attempted replantation and the rate of successful replantation per year. The independent variables included patients' age in groups ( $₫ 30$ years, 31-40 years, 41-60 years, and >60 years), sex, race (White, Black, Hispanic, other), Charlson comorbidity index $(0,1, \geq 2)$, insurance type (Medicare, Medicaid, private, other), median household income national quartile (Appendix A), hospital type (rural, urban nonteaching, urban teaching), hospital volume in groups ( $\$ 4$ cases, 5-15 cases, $>15$ cases), and the geographical region of the hospital (Northeast, Midwest, South, West).

\section{Data Analysis}

We adopted three possible treatment scenarios that a patient with traumatic digit amputation might undergo: successful replantation, failed replantation, and revision amputation. We defined a successful replantation by the sole presence of a replantation code (84.21 or 84.22). A failed replantation was defined as the presence of a replantation code along with a code for subsequent revision amputation $(84.01,84.02,84.3$, or 86.22). Claim files that had a traumatic digit amputation diagnosis code without any procedure code were interpreted as having undergone revision amputation.

We calculated the rate of replantation attempt and the rate of success each year to assess the trend over time, subcategorizing by digit and hospital types. We formed subgroups by digit type because the clinical indication for replantation is different for the thumb compared to the other digits, especially for single digit amputation cases. We performed a univariable analysis for the correlation between the rate of replantation attempt and patient and hospital characteristics. To assess the trend of centralization, we investigated the pattern of case 
distribution per hospital type each year. We also used two separate multivariable logistic regression models to examine patient and hospital characteristics that influenced the rate of replantation attempt and the rate of successful replantation.

\section{Results}

\section{Sample Characteristics}

From 2001 to 2014, we found that 14,872 adult patients had a single traumatic digit amputation and that 1,670 of them underwent digit replantation $(11.2 \%)$. The rate of replantation was similar among the subgroups for each variable including sex (male 11\%, female $10 \%$ ), race (White 11\%, Black 9\%, Hispanic 12\%, Other minorities 13\%), and hospital location (Northeast $11 \%$, Midwest $13 \%$, South $8 \%$, West $14 \%$ ). We found a significant association between replantation attempt and patient age, comorbidity index, insurance type, income quartile, and hospital type (Table 1). As the patient's age increased, the proportion of cases that underwent replantation decreased: $14 \%$ for patients age 30 or younger and $7 \%$ for patients older than 60 years. We also found that the rate of attempt decreased as the comorbidity index score increased. These relationships suggest that certain patient characteristics influence surgical treatment decisions. In regard to financial variables, the rate of replantation attempt was significantly higher for private insurance (13\%) compared to public insurance such as Medicare (5\%) or Medicaid (9\%). Similarly, as patients' income quartile increased, the rate of attempt increased. Urban teaching hospitals performed more replantation procedures (14\%) than rural (5\%) or urban non-teaching hospitals (6\%).

From our multivariable logistic regression analyses, we found that the odds of replantation attempt were also higher for higher income quartiles and for private insurance types compared to workers' compensation, government programs, Medicare, or Medicaid (Table 2). For instance, the odds of replantation were almost twice as high for patients with private insurance in comparison to patients with Medicare. Patients in the $4^{\text {th }}$ income quartile (the highest quartile) had 1.3 times higher odds of undergoing replantation than patients in the $1^{\text {st }}$ or $2^{\text {nd }}$ income quartiles. In other words, patients in the highest income bracket were $30 \%$ more likely to receive replantation for their amputated digits. These results reiterate that a patient's socioeconomic status has an association with the care received. The odds of attempted replantation were also higher for urban teaching hospitals (Odds Ratio 2.4, 95\% Confidence Interval 1.7-3.4, $\mathrm{p}<0.05$ ) than for rural hospitals. Thus, a digit amputation case presenting to an urban teaching hospital has a much higher likelihood to undergo replantation.

Our analysis on the odds of successful replantation did not reveal any significantly associated variables. Hospital type, hospital volume, and patient characteristics were not predictive of successful replantation ( $p>0.05)$.

\section{Rate of Replantation Attempt}

The rate of replantation attempt was $23.2 \%(818 / 3,519)$ for the thumb and $7.5 \%$ $(852 / 11,353)$ for other digits (Table 3$)$. We found a trend of decreasing rates of replantation 
attempt for both thumb and fingers. For thumb injuries, the rate of attempt in 2001 was $26.6 \%$ which decreased to $25.2 \%$ in 2006 and further decreased to $20.1 \%$ in 2014 (Figure 1a). Similarly, for finger injuries, the rate of attempt decreased from $8.4 \%$ (2001) to $6.2 \%$ (2006) to $5.5 \%$ in 2013. We observed a similar pattern for rural and urban teaching hospitals (Figure 1b). For rural hospitals, the rate of attempt decreased from $8.6 \%$ in 2001 to $1.9 \%$ in 2012, whereas for urban teaching hospitals it decreased from $17.1 \%$ in 2001 to $12.9 \%$ in 2014. The rate of attempt for urban non-teaching hospitals stayed relatively constant from $6.6 \%$ in 2001 to $6.2 \%$ in 2014 (Table 4).

\section{Rate of Successful Replantation}

We found that the rate of successful replantation over the study period was $83.4 \%(682 / 818)$ for the thumb and $77.3 \%$ (659/852) for the other digits (Table 3). The line of best fit showed that the rate of success remained relatively constant for thumb replantation and increased for finger replantation, in contrast to the decreasing trend of rate of attempt (Figure 2a). The rate of success for finger replantation was $71.9 \%$ in 2002 and $75.0 \%$ in 2007, which increased to $88.2 \%$ in 2013. After we subcategorized by hospital type, we also found an increasing trend for all three hospital types (Figure 2b). Over time, urban teaching hospital's success rate increased minimally but rural and urban non-teaching hospitals increased their success rates with digit replantation by roughly two-fold each year. The overall rates of successful replantation were comparable among all three hospital types: rural (82.5\%), urban nonteaching $(81.4 \%)$, and urban teaching $(80.0 \%)$ (Table 4$)$.

\section{Trend of Case Distribution}

Urban teaching hospitals treated $66.2 \%(9,804 / 14,872)$ of digit amputation cases, followed by $26.0 \%(3,858 / 14,872)$ at urban non-teaching hospitals and $7.7 \%(1,141 / 14,872)$ at rural hospitals (Table 4). We found that over time, an increasing proportion of cases were treated at urban teaching hospitals (Figure 3). In other words, traumatic digit amputation cases were progressively more centralized to large academic medical centers.

\section{Discussion}

Our study found that the proportion of amputation cases treated at urban teaching hospitals increased over the 14-year study period, from $56.9 \%$ in 2001 to $81.2 \%$ in 2014 . Owing to the limited availability of microvascular services and the complex nature of replantation surgery,

8,9 digit amputations presenting to small, rural hospitals are often transferred by helicopter to large, urban teaching hospitals. ${ }^{21,22}$ However, the cost benefit of this expensive practice was questionable, because nearly half of the urgently transferred patients were deemed ineligible for replantation. ${ }^{22}$ In 2006, the American College of Emergency Physicians changed policy on long-distance transport: the new protocol no longer considers traumatic digit amputation as an indication for air transfer. ${ }^{23}$ After the policy change, the number of transfers for replantation decreased by $50 \%$, but the clinical outcomes did not worsen for patients transferred by air post-2006. ${ }^{21}$ In addition, the reoperation and complication rates decreased after 2006. ${ }^{21}$ Thus, this was an improvement in cost-efficiency and resource utilization. In our study, urban teaching hospitals treated 58.5\% of amputation cases in 2005, and in 2007 the proportion increased to $68.6 \%$. We found similar rates of success among the different 
hospital types, but this probably reflects appropriate triaging of cases by severity. In other words, less severe cases were probably appropriately treated at rural and urban non-teaching hospitals, and cases that needed higher level of care were likely sent to urban teaching hospitals. Urban teaching hospitals are more likely to be level-1 trauma centers with microvascular services, ${ }^{24,25}$ and thus our results serve as evidence of appropriate centralization for digit replantation. It indicates an improvement in delivery of care as well, as a higher number of indicated cases of replantation would have the opportunity to undergo replantation. ${ }^{11}$

Our analysis of updated U.S. data found that the rate of replantation has decreased over the 14-year study period for both thumb and fingers, and at all hospital types. This is a continuation of the downward trend demonstrated in the past. ${ }^{15}$ In fact, our result of $11.2 \%$ is much lower than $15.6 \%$ and $18 \%$ from past studies that also examined single digit replantation rates with data up to $2012 .{ }^{15,16}$ The continued decrease in the rate of replantation is in spite of the 2013 mandate by the American College of Surgeons to make microvascular service available at all times at level-1 trauma centers in the U.S. ${ }^{19}$ The expectation was to increase the rate of digit replantation by concentrating the case volume. ${ }^{15}$ However, our study results, showing a continued decrease in rate of replantation, is evidence that centralization is not a "cure all" for improving replantation rates.

The factors that could influence a surgeon's decision to replant include disruption of work schedule, inadequate confidence in surgical skill, and inadequate reimbursement rate. ${ }^{10,13,26}$ The decreasing rates of replantation attempt in conjunction with the increase in rate of success, found in our study, indicate that surgeons may have become more selective in choosing cases to perform replantation. In fact, we found that a patient's insurance type and income status influenced whether or not the amputated digit underwent replantation. In comparison to patients with Medicare or Medicaid, patients with private insurance were twice more likely to receive replantation. Other studies have shown similar results. ${ }^{13,26}$ Insurance type is directly related to reimbursement rate; private insurances have two to four times higher rate of reimbursement than public insurances for surgical procedures. ${ }^{27,28}$ Furthermore, a 2017 study of emergency department wait times showed that patients with public or no insurance experienced longer wait times, which were associated with lower odds of replantation..$^{29}$ These results indicate that a surgeon's financial incentives may influence surgical decision making, but we also need to consider that patients with a lower socioeconomic status are more likely to have public insurance and thus elect to undergo a revision amputation procedure that costs less and requires shorter recovery, so that they can return to work quickly. ${ }^{22}$ In other words, patients with limited financial resources may forego a recommended treatment option. Our study results demonstrate that financial aspects of digit replantation are important and should be addressed to reverse the declining trend in digit replantation.

Because of the nature of claims data, this study has several limitations, including the inherent uncertainty and variation in coding practice. For replantation attempts that were aborted intraoperatively, the categorization would depend on how the procedure was coded, case by case. If both replantation code and revision amputation codes exist, then it would be classified as a failed replantation. If only the code for revision amputation exist, then it 
would be categorized as a revision amputation without a replantation attempt. Owing to the limits of ICD-9 coding scheme, we could only include single digit amputation cases in our cohort because we could not determine the outcome of replantation for each digit for patients with multiple amputated digits. Rather than assuming the success or failure of replantation, we decided to only include cases for which we could confidently determine the outcome. We believe that limiting our study cohort to single amputation cases enabled a more transparent data analysis with a homogeneous sample. Another limiting factor was the inability to track patients beyond a single hospital admission because of the absence of a patient identifier element in the NIS. In other words, if a patient experienced postoperative complications after discharge, it was not captured in our analysis. However, most late complications of digit replantation are tendon adhesions, mal-union, nonunion, neuroma, and cold intolerance, rather than failure of revascularization. ${ }^{17,30}$ Therefore, we believe that our methodology to define a successful replantation is the best available for this dataset. In addition, because we could not track a patient beyond a single inpatient stay, our definition of successful replantation is limited to initial vascular survival of the replanted segment. Thus, our results cannot be compared to other studies on digit replantation that assessed functional outcomes. Lastly, as the NIS collects data from inpatient stays, patients who underwent revision amputation without a subsequent hospital admission were not captured in our analysis. This may have led to overestimation of the rate of replantation attempt, however, this actually amplifies the meaning of our result of low rate of replantation attempt.

Traumatic digit amputations have a devastating impact on patients' functional status and aesthetic confidence, yet rates of digit replantation have continued to fall. Although more single digit amputations were treated by urban teaching hospitals with higher volume and higher likelihood to replant, the decreasing trend in rate of attempt demonstrates that other influential factors besides centralization need to be addressed to improve the rates of digit replantation.

\section{Supplementary Material}

Refer to Web version on PubMed Central for supplementary material.

\section{Acknowledgments}

Funding: Funding for this work was supported by a Midcareer Investigator Award (2 K24-AR053120-06) to Dr. Kevin C. Chung from the National Institute of Arthritis and Musculoskeletal and Skin Diseases of the National Institutes of Health.

\section{References}

1. Rui P, Kang K. CDC National Hospital Ambulatory Medical Care Survey: 2015 Emergency Department Summary Tables.https://www.cdc.gov/nchs/data/nhamcs/web tables/2015 ed web tables.pdf. Accessed July 18th, 2018

2. Bastidas N, Cassidy L, Hoffman L, Sharma S. A single-institution experience of hand surgery litigation in a major replantation center. Plast Reconstr Surg 2011;127(1):284-292. [PubMed: 21200222]

3. de Putter CE, Selles RW, Polinder S, Panneman MJ, Hovius SE, van Beeck EF. Economic impact of hand and wrist injuries: health-care costs and productivity costs in a population-based study. J Bone Joint Surg Am 2012;94(9):e56. [PubMed: 22552678] 
4. Waikakul S, Vanadurongwan V, Unnanuntana A. Prognostic factors for major limb re-implantation at both immediate and long-term follow-up. J Bone Joint Surg Br 1998;80(6): 1024-1030. [PubMed: 9853497]

5. Tessler O, Bartow MJ, Tremblay-Champagne MP, et al. Long-Term Health-Related Quality of Life Outcomes in Digital Replantation versus Revision Amputation. J Reconstr Microsurg 2017;33(6): 446-451. [PubMed: 28329874]

6. Hattori Y, Doi K, Ikeda K, Estrella EP. A retrospective study of functional outcomes after successful replantation versus amputation closure for single fingertip amputations. J Hand Surg Am 2006;31(5):811-818. [PubMed: 16713848]

7. Nishizuka T, Shauver MJ, Zhong L, Chung KC, Hirata H. A Comparative Study of Attitudes Regarding Digit Replantation in the United States and Japan. J Hand Surg Am 2015;40(8): 16461656, 1656.e1641-1643. [PubMed: 26213200]

8. Rao MB, Lerro C, Gross CP. The shortage of on-call surgical specialist coverage: a national survey of emergency department directors. Acad Emerg Med 2010;17(12):1374-1382. [PubMed: 21091822]

9. Peterson BC, Mangiapani D, Kellogg R, Leversedge FJ. Hand and microvascular replantation call availability study: a national real-time survey of level-I and level-II trauma centers. J Bone Joint Surg Am 2012;94(24):e185. [PubMed: 23318624]

10. Payatakes AH, Zagoreos NP, Fedorcik GG, Ruch DS, Levin LS. Current practice of microsurgery by members of the American Society for Surgery of the Hand. J Hand Surg Am 2007;32(4):541547. [PubMed: 17398366]

11. Mahmoudi E, Chung KC. Effect of Hospital Volume on Success of Thumb Replantation. J Hand Surg Am 2017;42(2):96-103.e105. [PubMed: 28027844]

12. Chung KC, Kowalski CP, Walters MR. Finger replantation in the United States: rates and resource use from the 1996 Healthcare Cost and Utilization Project. J Hand Surg Am 2000;25(6):10381042. [PubMed: 11119660]

13. Friedrich JB, Poppler LH, Mack CD, Rivara FP, Levin LS, Klein MB. Epidemiology of upper extremity replantation surgery in the United States. J Hand Surg Am 2011;36(11):1835-1840. [PubMed: 21975098]

14. Shale CM, Tidwell JE, 3rd, Mulligan RP, Jupiter DC, Mahabir RC. A nationwide review of the treatment patterns of traumatic thumb amputations. Ann Plast Surg 2013;70(6):647-651. [PubMed: 23673564]

15. Hustedt JW, Bohl DD, Champagne L. The Detrimental Effect of Decentralization in Digital Replantation in the United States: 15 Years of Evidence From the National Inpatient Sample. J Hand Surg Am 2016;41(5):593-601. [PubMed: 27021636]

16. Brown M, Lu Y, Chung KC, Mahmoudi E. Annual Hospital Volume and Success of Digital Replantation. Plast Reconstr Surg 2017;139(3):672-680. [PubMed: 28234846]

17. Mulders MA, Neuhaus V, Becker SJ, Lee SG, Ring DC. Replantation and revascularization vs. amputation in injured digits. Hand (N Y). 2013;8(3):267-273. [PubMed: 24426933]

18. Fufa D, Calfee R, Wall L, Zeng W, Goldfarb C. Digit replantation: experience of two U.S. academic level-I trauma centers. J Bone Joint Surg Am 2013;95(23):2127-2134. [PubMed: 24306700]

19. Resources for Optimal Care of the Injured Patient. Chicago: American College of Surgeons; 2013.

20. Overview of the National (Nationwide) Inpatient Sample (NIS). Agency for Healthcare Research and Quality Web Site. www.hcup-us.ahrq.gov/nisoverview. Accessed November 1st, 2017.

21. Nolte MT, Shauver MJ, Chung KC, Giladi AM. Effect of Policy Change on the Use of LongDistance Transport and Follow-Up Care for Patients With Traumatic Finger Amputations. J Hand Surg Am 2017;42(8):610-617.e612. [PubMed: 28499510]

22. Ozer K, Kramer W, Gillani S, Williams A, Smith W. Replantation versus revision of amputated fingers in patients air-transported to a level 1 trauma center. J Hand Surg Am 2010;35(6):936-940. [PubMed: 20488629]

23. American College of Emergency Physicians and National Association of EMS Physicians.Guidelines for air medical dispatch. Policy Resource and Education Paper. . 12006. 
24. MacKenzie EJ, Hoyt DB, Sacra JC, et al. National inventory of hospital trauma centers. Jama. 2003;289(12):1515-1522. [PubMed: 12672768]

25. Colleges AoAM. Why Teaching Hospitals are Important to Americans. https://www.aamc.org/ download/253382/data/teaching-hospitals.pdf. Accessed July 18, 2018.

26. Squitieri L, Reichert H, Kim HM, Steggerda J, Chung KC. Patterns of surgical care and health disparities of treating pediatric finger amputation injuries in the United States. J Am Coll Surg 2011;213(4):475-485. [PubMed: 21856185]

27. Krause TM, Ukhanova M, Revere FL. Private Carriers' Physician Payment Rates Compared With Medicare and Medicaid. Tex Med 2016;112(6):e1.

28. Odom EB, Schmidt AC, Myckatyn TM, Buck DW, 2nd. A Cross-Sectional Study of Variations in Reimbursement for Breast Reconstruction: Is A Healthcare Disparity On the Horizon? Ann Plast Surg 2018;80(3):282-286. [PubMed: 28984659]

29. Mahmoudi E, Swiatek PR, Chung KC. Emergency Department Wait Time and Treatment of Traumatic Digit Amputation: Do Race and Insurance Matter? Plast Reconstr Surg 2017;139(2): $444 \mathrm{e}-454 \mathrm{e}$.

30. Soucacos PN. Indications and selection for digital amputation and replantation. J Hand Surg Br 2001;26(6): 572-581. [PubMed: 11884116] 


\section{Clinical Relevance :}

Financial aspects of digit replantation need to be considered from both the patients and the surgeons' perspectives to improve delivery of care for digit replantation. 
1a.

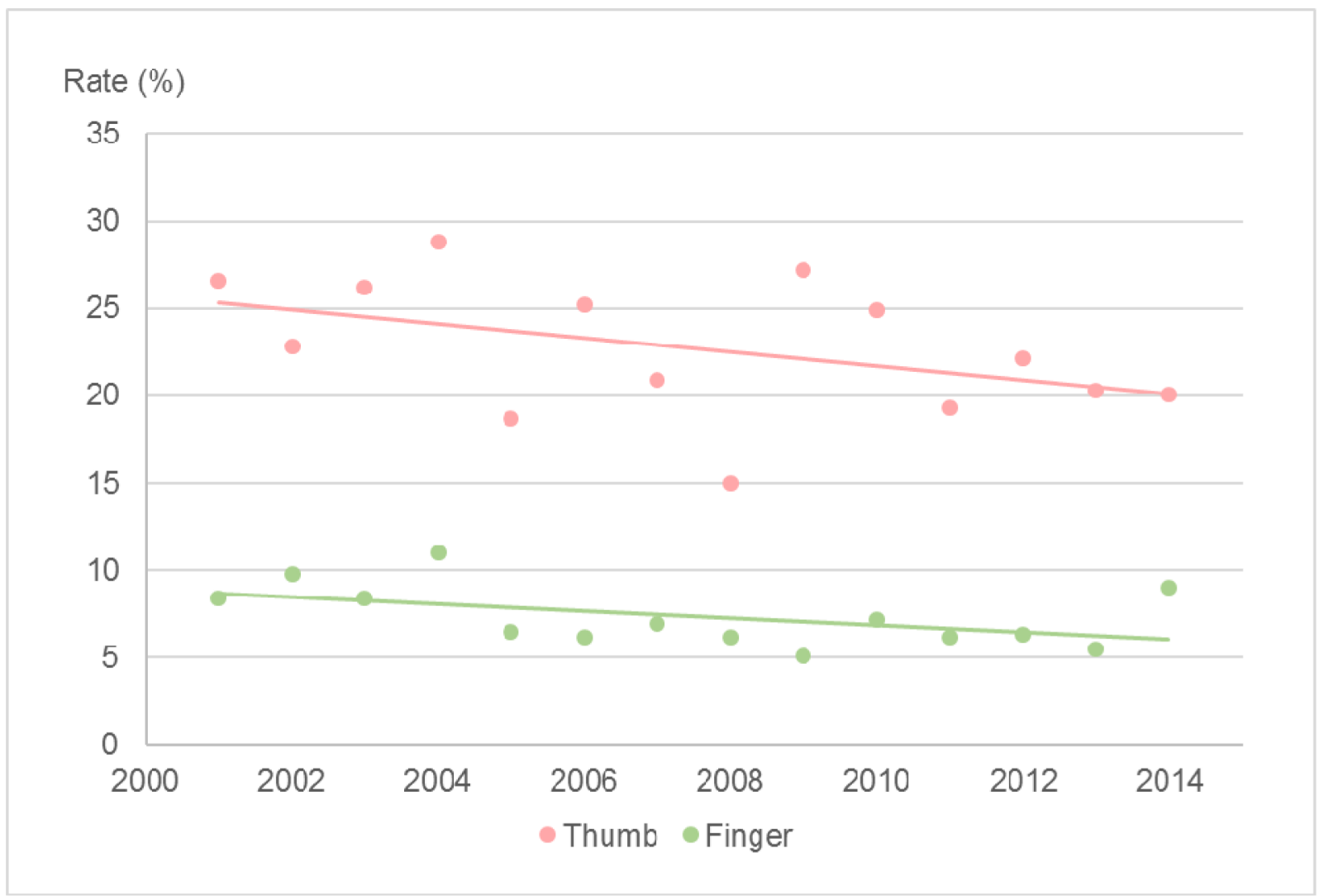


$1 b$.

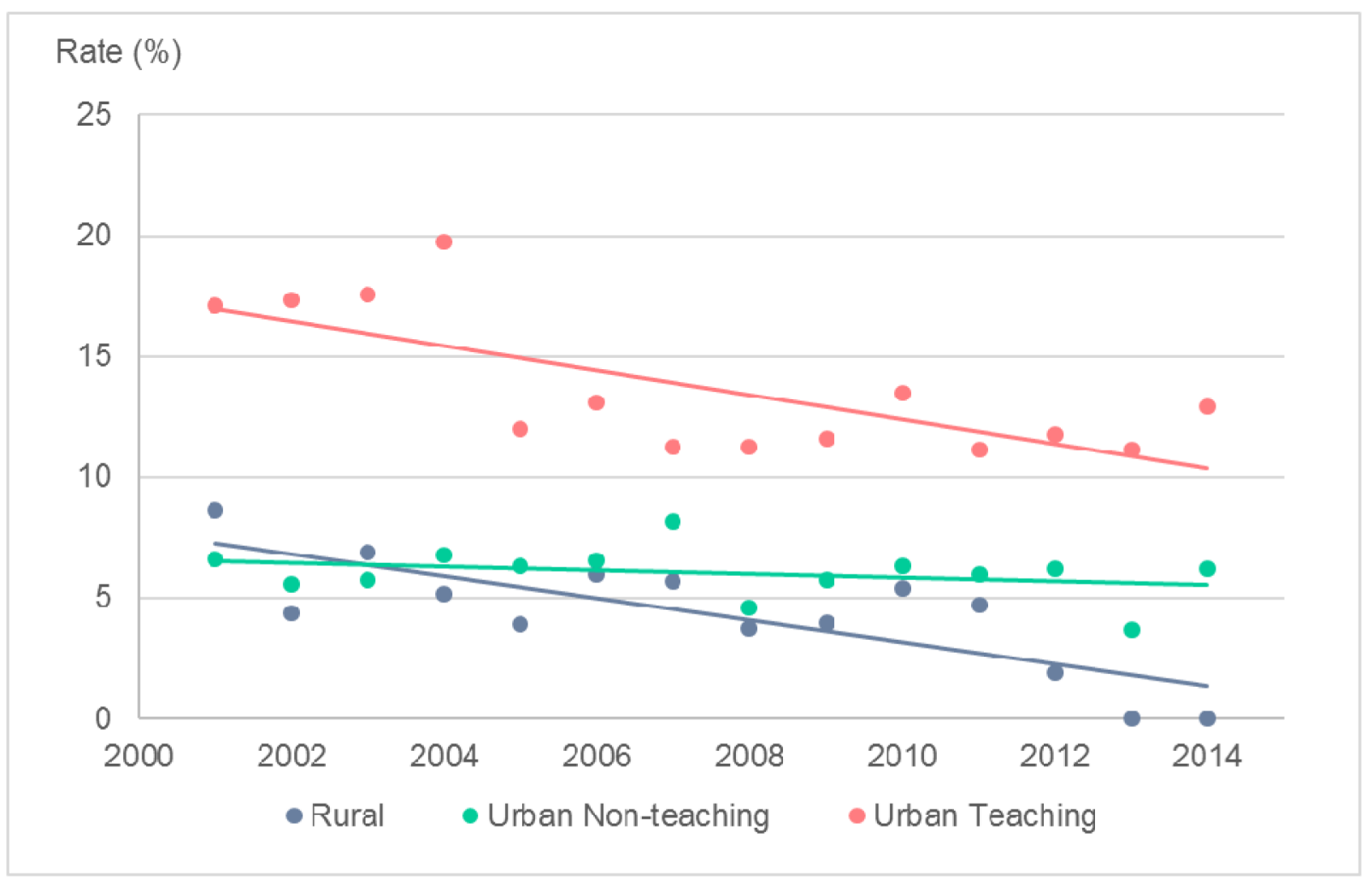

Figure 1a.

Rate of Replantation Attempt (2001 - 2014) by Digit Type

1b. Rate of Replantation Attempt (2001 - 2014) by Hospital Type

J Hand Surg Am. Author manuscript; available in PMC 2019 October 01. 
$2 \mathrm{a}$.

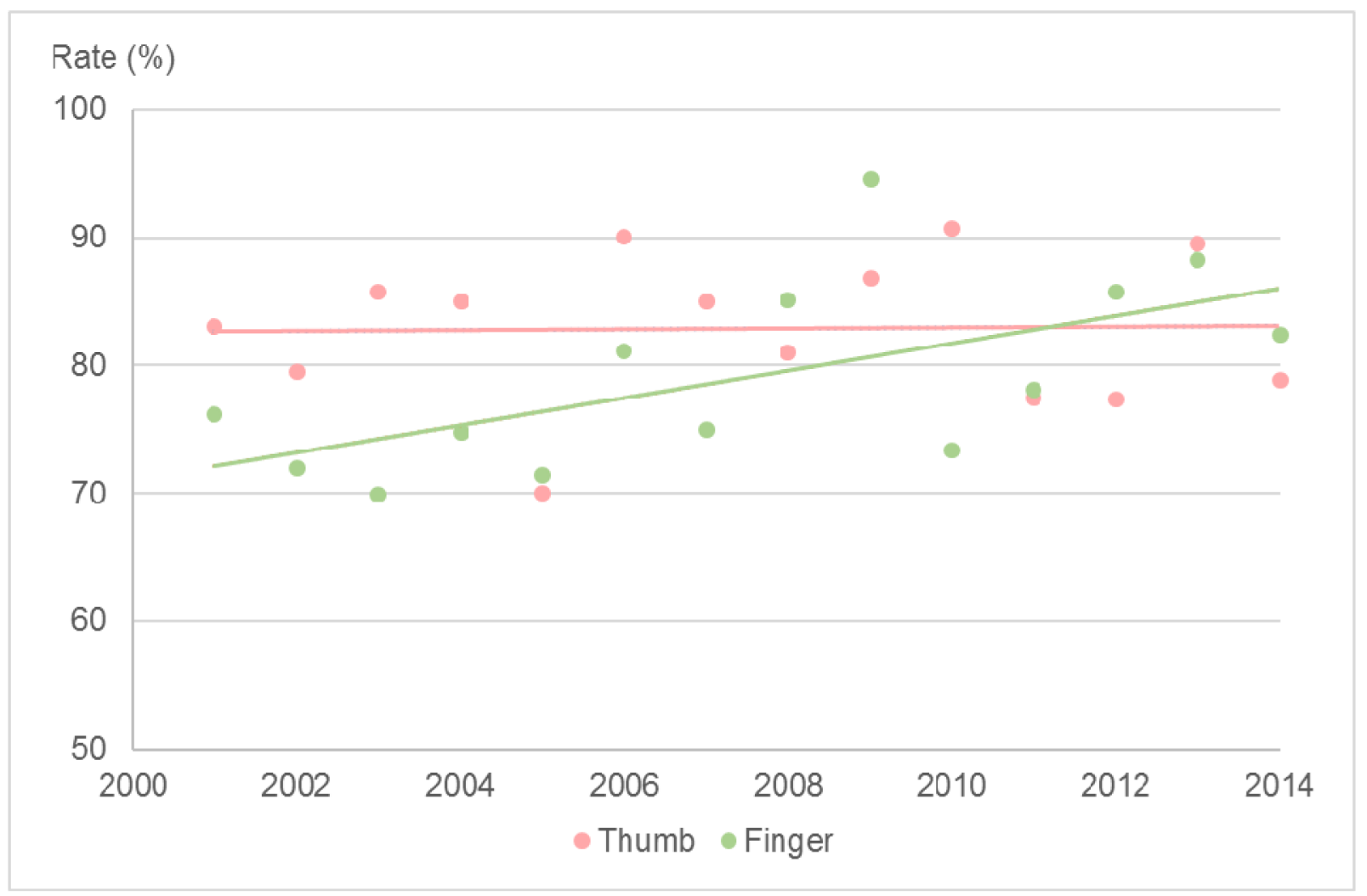


$2 b$.

Rate $(\%)$

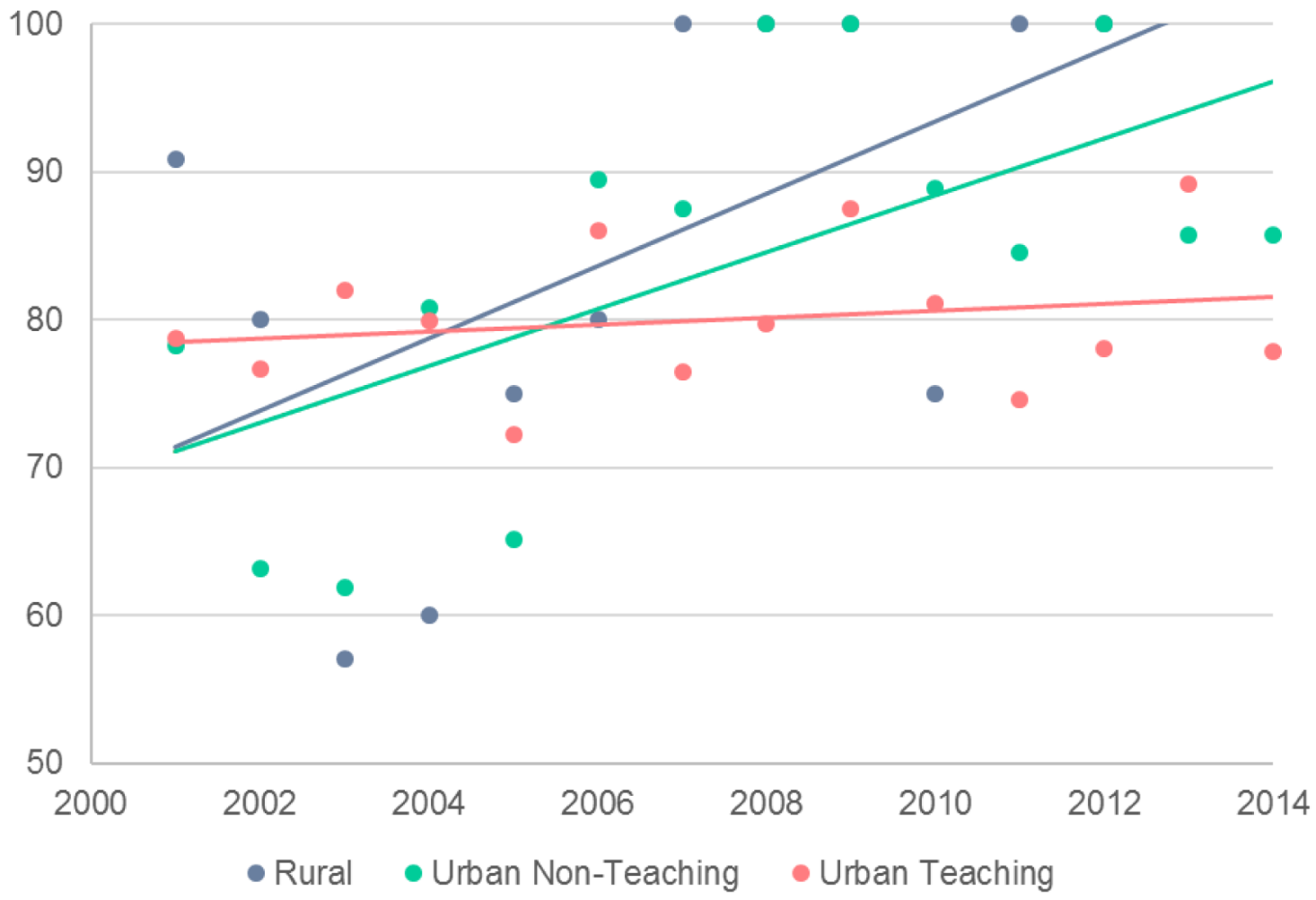

Figure 2a.

Rate of Successful Replantation (2001 - 2014) by Digit Type

2b. Rate of Successful Replantation (2001 - 2014) by Hospital Type

J Hand Surg Am. Author manuscript; available in PMC 2019 October 01. 

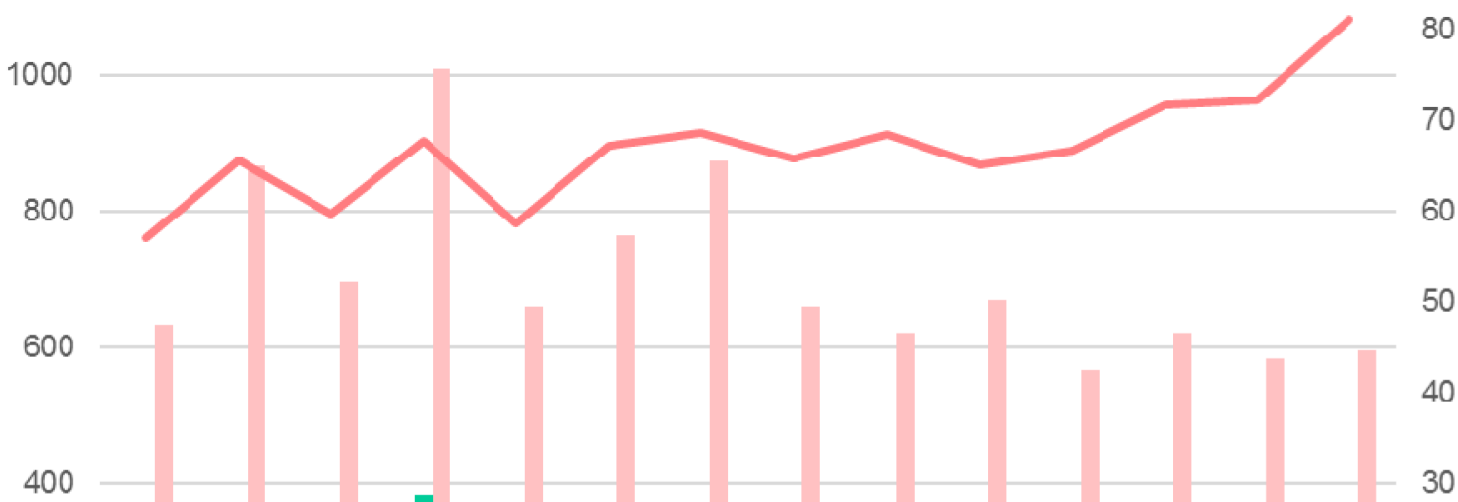

$\begin{array}{llllllllllllll}2001 & 2002 & 2003 & 2004 & 2005 & 2006 & 2007 & 2008 & 2009 & 2010 & 2011 & 2012 & 2013 & 2014\end{array}$

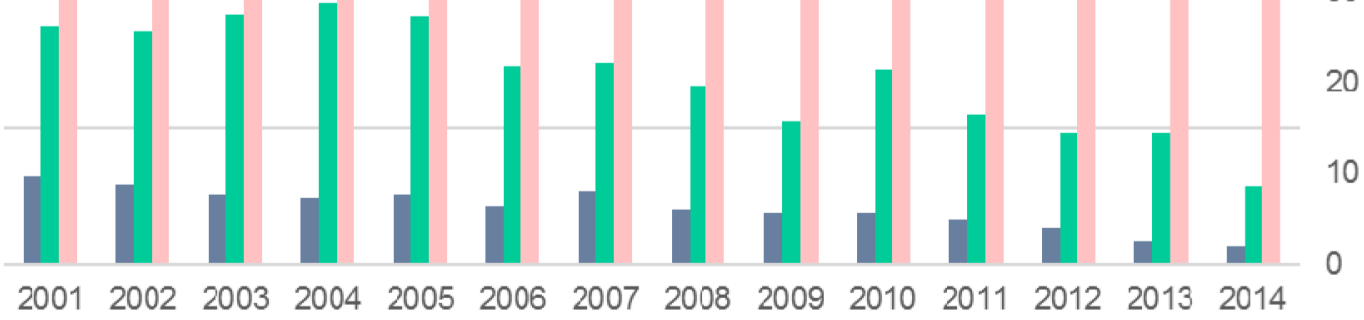

Rural Urban Non-Teaching Urban Teaching — Case Volume for Urban Teaching

Figure 3.

Case Distribution per Hospital Type (2001 - 2014) 
Table 1.

Rate of Replantation by Patient and Hospital Characteristics

\begin{tabular}{|c|c|c|}
\hline Variables & Attempted Replantation (N(\%)) & No Replantation (N(\%)) \\
\hline \multicolumn{3}{|l|}{ Age } \\
\hline$\leq 30$ & $507(14 \%)$ & $3,110(86 \%)$ \\
\hline $31-40$ & $352(12 \%)$ & $2,544(88 \%)$ \\
\hline $41-60$ & $641(11 \%)$ & $5,134(89 \%)$ \\
\hline$>60$ & $170(7 \%)$ & $2,414(93 \%)$ \\
\hline \multicolumn{3}{|l|}{ Sex } \\
\hline Male & $1,479(11 \%)$ & $11,556(89 \%)$ \\
\hline Female & $174(10 \%)$ & $1,573(90 \%)$ \\
\hline \multicolumn{3}{|l|}{ Race } \\
\hline White & $786(11 \%)$ & $6,510(89 \%)$ \\
\hline Black & $99(9 \%)$ & $1,034(91 \%)$ \\
\hline Hispanic & $336(12 \%)$ & $2,518(88 \%)$ \\
\hline Other minorities & $129(13 \%)$ & $847(87 \%)$ \\
\hline \multicolumn{3}{|c|}{ Charlson Comorbidity Index } \\
\hline 0 & $1,475(12 \%)$ & $11,253(88 \%)$ \\
\hline 1 & $174(11 \%)$ & $1,482(89 \%)$ \\
\hline$\geq 2$ & $21(4 \%)$ & $467(96 \%)$ \\
\hline \multicolumn{3}{|l|}{ Insurance Type ${ }^{t}$} \\
\hline Medicare & $102(5 \%)$ & $1,812(95 \%)$ \\
\hline Medicaid & $92(9 \%)$ & $916(91 \%)$ \\
\hline Private Insurance & $623(13 \%)$ & $4,170(87 \%)$ \\
\hline Other Insurance & $850(12 \%)$ & $6,240(88 \%)$ \\
\hline \multicolumn{3}{|c|}{ Median Household Income National Quartile $\xi$} \\
\hline Quartile 1 & $351(9 \%)$ & $3,435(91 \%)$ \\
\hline Quartile 2 & $403(11 \%)$ & $3,300(89 \%)$ \\
\hline Quartile 3 & $390(11 \%)$ & $3,077(89 \%)$ \\
\hline Quartile 4 & $463(14 \%)$ & $2,959(86 \%)$ \\
\hline \multicolumn{3}{|l|}{ Location } \\
\hline Northeast & $294(11 \%)$ & $2,418(89 \%)$ \\
\hline Midwest & $331(13 \%)$ & $2,227(87 \%)$ \\
\hline South & $481(8 \%)$ & $5,262(92 \%)$ \\
\hline West & $488(14 \%)$ & $2,985(86 \%)$ \\
\hline \multicolumn{3}{|l|}{ Hospital type } \\
\hline Rural & $57(5 \%)$ & $1,086(95 \%)$ \\
\hline Urban Non-Teaching & $236(6 \%)$ & $3,619(94 \%)$ \\
\hline Urban Teaching & $1,370(14 \%)$ & $8,434(86 \%)$ \\
\hline
\end{tabular}

J Hand Surg Am. Author manuscript; available in PMC 2019 October 01. 
FPrivate Insurance category includes Blue Cross, commercial carriers, private HMOs and PPOs (Health Maintenance Organizations and Preferred Provider Organizations). Other Insurance category includes worker's compensation and government programs.

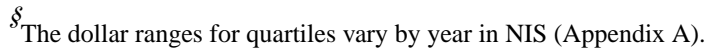


Table 2.

Multivariable Analysis on the Influence of Patient and Hospital Characteristics on Replantation Attempt

\begin{tabular}{|c|c|c|}
\hline Variables & Odds Ratios (95\% CI) & $P$ values \\
\hline \multicolumn{3}{|l|}{ Age } \\
\hline$\leq 30$ & 1 & - \\
\hline $31-40$ & $0.9(0.7,1.0)$ & 0.13 \\
\hline $41-60$ & $0.8(0.7,0.9)$ & $<0.05$ \\
\hline$>60$ & $0.6(0.5,3.4)$ & $<0.05$ \\
\hline \multicolumn{3}{|l|}{ Sex } \\
\hline Male & 1 & - \\
\hline Female & $0.8(0.7,1.0)$ & $<0.05$ \\
\hline \multicolumn{3}{|l|}{ Race } \\
\hline White & 1 & - \\
\hline Black & $0.9(0.7,1.1)$ & 0.19 \\
\hline Hispanic & $1(0.8,1.1)$ & 0.72 \\
\hline Other minorities & $1.3(1.0,1.6)$ & $<0.05$ \\
\hline \multicolumn{3}{|c|}{ Charlson Comorbidity Index } \\
\hline 0 & 1 & - \\
\hline 1 & $1.2(0.9,1.4)$ & 0.15 \\
\hline$\geq 2$ & $0.5(0.3,0.9)$ & $<0.05$ \\
\hline \multicolumn{3}{|l|}{ Insurance Type } \\
\hline Medicare & 1 & - \\
\hline Medicaid & $1.1(0.7,1.6)$ & 0.66 \\
\hline Private Insurance & $1.9(1.4,2.6)$ & $<0.05$ \\
\hline Other Insurance & $1.6(1.2,2.2)$ & $<0.05$ \\
\hline \multicolumn{3}{|c|}{ Median Household Income National Quartile } \\
\hline Quartile 1 & 1 & - \\
\hline Quartile 2 & $1(0.8,1.2)$ & 0.98 \\
\hline Quartile 3 & $1.1(0.9,1.3)$ & $\overline{0.48}$ \\
\hline Quartile 4 & $1.3(1.1,1.5)$ & $<0.05$ \\
\hline \multicolumn{3}{|l|}{ Location } \\
\hline Northeast & 1 & - \\
\hline Midwest & $1.4(1.1,1.7)$ & $<0.05$ \\
\hline South & $0.8(0.7,1.0)$ & $<0.05$ \\
\hline West & $1.6(1.4,1.9)$ & $<0.05$ \\
\hline \multicolumn{3}{|l|}{ Hospital type } \\
\hline Rural & 1 & - \\
\hline Urban Non-Teaching & $1.1(0.7,1.6)$ & 0.70 \\
\hline Urban Teaching & $2.4(1.7,3.4)$ & $<0.05$ \\
\hline
\end{tabular}

J Hand Surg Am. Author manuscript; available in PMC 2019 October 01. 
Table 3.

Numbers of Traumatic Digit Amputations, Replantation Attempts, and Successful Cases per Year per Digit Type $(\mathrm{N})^{\dagger}$

\begin{tabular}{|r|r|r|r|r|r|r|r|r|}
\hline & \multicolumn{5}{|c|}{ Thumb } & \multicolumn{4}{|c|}{ Fingers } \\
\hline Year & Injured & Attempted & Success & Failed & Injured & Attempted & Success & Failed \\
\hline 2001 & 267 & 71 & 59 & 12 & 843 & 71 & 54 & 17 \\
\hline 2002 & 342 & 78 & 62 & 16 & 979 & 96 & 69 & 27 \\
\hline 2003 & 294 & 77 & 66 & 11 & 867 & 73 & 51 & 22 \\
\hline 2004 & 371 & 107 & 91 & 16 & 1,118 & 123 & 92 & 31 \\
\hline 2005 & 267 & 50 & 35 & 15 & 857 & 56 & 40 & 16 \\
\hline 2006 & 282 & 71 & 64 & 7 & 856 & 53 & 43 & 10 \\
\hline 2007 & 287 & 60 & 51 & 9 & 985 & 68 & 51 & 17 \\
\hline 2008 & 240 & 42 & 34 & 8 & 760 & 47 & 40 & 7 \\
\hline 2009 & 195 & 53 & 46 & 7 & 730 & 37 & 35 & 2 \\
\hline 2010 & 217 & 54 & 49 & 5 & 838 & 60 & 44 & 16 \\
\hline 2011 & 207 & 40 & 31 & 9 & 663 & 41 & 32 & 9 \\
\hline 2012 & 199 & 44 & 34 & 10 & 667 & 42 & 36 & 6 \\
\hline 2013 & 187 & 38 & 34 & 4 & 621 & 64 & 30 & 4 \\
\hline 2014 & 164 & 33 & 26 & 7 & 569 & 51 & 42 & 9 \\
\hline Total & 3,519 & 818 & 682 & 136 & 11,353 & 852 & 659 & 193 \\
\hline \multirow{2}{*}{} & & & & & & & & \\
\hline
\end{tabular}

${ }^{\dagger}$ The numbers reported here are unweighted. 
로을

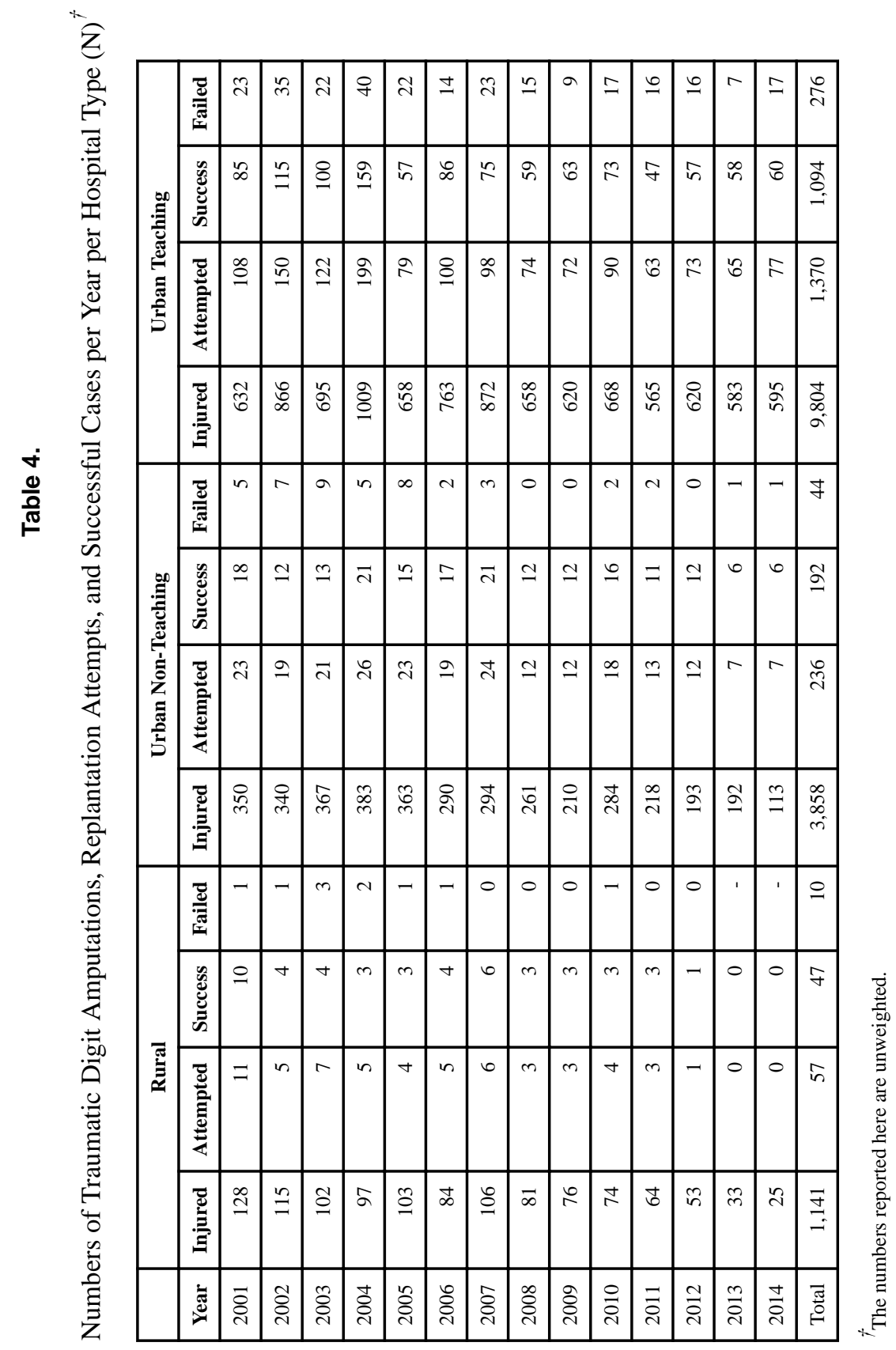

J Hand Surg Am. Author manuscript; available in PMC 2019 October 01. 